Удк 581.192:577.118

\title{
НАКОПЛЕНИЕ ЭССЕННЦИАЛЬНЫХ ЭЛЕМЕНТОВ И СВИНЦА В ПЛОДАХ И ВЕГЕТАТИВНЫХ ЧАСТЯХ ОБЛЕПИХИ
}

\author{
(C) Г.М. Скуридин ${ }^{1 *}$ О.В. Чанкина ${ }^{2}$, Н.В. Багинская ${ }^{3}$ \\ ${ }^{1}$ Центральный сибирский ботанический сад СО РАН, ул. Золотодолинская, \\ 101, Новосибирск, 630090 (Россия), e-mail: skuridin@bionet.nsc.ru \\ ${ }^{2}$ Институт химической кинетики и горения СО РАН, ул. Институтская, 3 , \\ Новосибирск, 630090 (Россия) \\ ${ }^{3}$ Институт цитологии и генетики СО РАН, пр. Лаврентьева, 10, \\ Новосибирск, 630090 (Россия)
}

Плоды облепихи крушиновидной (Hippophae rhamnoides L.) широко используются в России и за рубежом как сырье для производства пищевой продукции, медицинских препаратов и биологически активных пищевых добавок. В облепихе найдено более 200 биологически активных органических компонентов, однако ее минеральный состав исследован недостаточно.

Изучали элементный состав плодов, листьев, коры и корней нескольких сортов облепихи крушиновидной (Hippophae rhamnoides L. ssp. mongolica (Rousi)), а также почвы с места их произрастания. Методом РФА-СИ (рентгенофлуоресцентный анализ с использованием синхротронного излучения) количественно определяли концентрацию жизненно необходимых (эссенциальных) $\mathrm{Fe}, \mathrm{Mn}, \mathrm{Zn}, \mathrm{Cu}, \mathrm{Cr}, \mathrm{Co}, \mathrm{Mo}$, Se и токсичного Рb. Интенсивность аккумуляции элементов в тканях определялась по коэффициенту их биологического поглощения из почвы.

Все части растения облепихи характеризуются высокой интенсивностью поглощения хрома, недостаток которого способствует развитию атеросклероза, метаболического синдрома и диабета. По содержанию $\mathrm{Cr}$ облепиха превосходит широко известные лекарственные растения - жимолость синюю (Lonicera caerulea ssp. altaica (Pall.) и пятилистник кустарниковый (курильский чай, Pentaphylloides fructicosa (L.). Поэтому не только плоды, но также листья, кора и корни облепихи могут служить ценным сырьем для производства лечебно-профилактической продукции, обогащенным биогенным хромом.

Показано, что интенсивность поглощения почвенного свинца облепихой не превышает этого показателя у других растений.

Ключевые слова: облепиха крушиновидная, микроэлементы, синхротронное излучение.

\section{Введение}

Плоды и листья облепихи крушиновидной (Hippophae rhamnoides L.) широко используются в России и за рубежом как сырье для производства разнообразной пищевой продукции, лечебно-профилактических и медицинских препаратов, биологически активных пищевых добавок (БАД) [1]. Широта биологической активности облепиховой продукции дает основания полагать, что в тканях облепихи может быть повышено содержание жизненно необходимых (эссенциальных) минеральных элементов, так как многие ферменты, гормоны, витамины и другие биологически активные вещества (БАВ), поступающие с растительной пищей, представляют собой органоминеральные комплексы. Между тем микроэлементный состав тканей облепихи крушиновидной исследован недостаточно.

Скуридин Геннадий Михайлович - кандидат биологических наук, научный сотрудник, e-mail: skuridin@bionet.nsc.ru

Чанкина Ольга Васильевна - кандидат химических наук, старший научный сотрудник,

e-mail: chankina@ns.kinetics.nsc.ru

Багинская Нина Владиславовна - научный сотрудник, e-mail: bagin@bionet.nsc.ru
Современный рацион питания рафинированными продуктами способствует хроническому дефициту эссенциальных элементов [2]. Прием простых минеральных солей зачастую малоэффективен ввиду слабой ассимиляции и нежелательных побочных эффектов химически чистых соединений. Есте-

\footnotetext{
* Автор, с которым следует вести переписку.
} 
ственные органоминеральные комплексы с благоприятным для организма соотношением компонентов обычно лишены недостатков чистых солей [3].

Цель данного исследования - количественное определение микроэлементного состава облепихи крушиновидной как природного источника эссенциальных микроэлементов и возможного аккумулятора свинца - основного минерального загрязнителя почв. Для этого проводилось изучение минерального состава плодов, листьев, коры и корней облепихи, а также почвы.

\section{Экспериментальная часть}

Исследовали зрелые плоды, зеленые листья, кору и корни сибирской облепихи (Hippophae rhamnoides L. ssp. mongolica (Rousi) четырех сортов (Зарница, Зырянка, Красный Факел, Сибирский Румянец), произрастающих на экологически чистом участке окрестностей Новосибирска, а также почву этого участка. Забор проб осуществляли в стандартные сроки сбора соответствующего лекарственного сырья. Предварительно определяли влажность образцов, после чего обезвоженный материал размельчали до порошкообразного состояния и отбирали образец массой 30 мг для анализа.

Элементный анализ проводили рентгенофлуоресцентным методом с использованием синхротронного излучения (РФА-СИ) в Сибирском ЦКП синхротронного и терагерцового излучения на установке и по методике, описанных в работе [4]. Метод официально аттестован ФГУП «Уральский научноисследовательский институт метрологии» (Свид. № 253.11.09.343/2006). В данном случае определяли количественное содержание эссенциальных $\mathrm{Fe}, \mathrm{Cr}, \mathrm{Mn}, \mathrm{Zn}, \mathrm{Cu}, \mathrm{Co}, \mathrm{Mo}, \mathrm{Se}$, а также Pb.

Особенности накопления элементов у облепихи выявляли путем сравнения с результатами анализа методом РФА-СИ дикорастущих растений - источников БАВ: жимолости синей (Lonicera caerulea subsp. altaica (Pall.) Gladkova), пятилистника кустарникового (курильского чая, Pentaphylloides fructicosa (L.) O. Schwarz) и чины весенней (Lathyrus (Orobus) vernus (L.) Bernh) из экологически чистых районов [5-7].

Оценка способности к накоплению элементов в зависимости от степени загрязненности почвы в разных регионах проводилась с привлечением данных по элементному составу плодов облепихи на различном удалении от автомобильной трассы [8].

Рекомендуемый уровень суточного потребления микроэлементов приводится по официальным нормам физиологических потребностей в энергии и пищевых веществах для различных групп населения РФ [9]. Допустимый уровень содержания свинца - по гигиеническим нормативам для свежих фруктов и ягод и сухих БАД на основе растительного сырья [10].

\section{Результатьи и обсуждение}

В таблице 1 представлены результаты анализа концентрации химических элементов в сыром веществе.

Железо. Этот важнейший микроэлемент характеризуется максимальным содержанием в корнях. В 100 г свежих корней облепихи содержится двойная суточная норма железа.

Марганец. Максимальное количество элемента накапливают листья облепихи. В количестве 100 г они полностью покрывают суточную потребность в марганце.

Таблица 1. Концентрация химических элементов в сыром веществе надземных органов и корней облепихи, мг/кг

\begin{tabular}{c|c|c|c|c|c}
\hline Элемент & Плоды & Листья & Кора & Корни & СНП \\
\hline $\mathrm{Fe}$ & $9,5 \pm 1,9$ & $37 \pm 2$ & $22 \pm 3$ & $227 \pm 64$ & 10 \\
$\mathrm{Mn}$ & $2,2 \pm 0,2$ & $26 \pm 1$ & $4,0 \pm 0,02$ & 2,3 & 2 \\
$\mathrm{Zn}$ & $2,4 \pm 0,3$ & $4,0 \pm 1,0$ & $2,0 \pm 0,2$ & $2,0 \pm 0,2$ & 12 \\
$\mathrm{Cu}$ & $0,4 \pm 0,02$ & $0,5 \pm 0,03$ & $0,5 \pm 0,02$ & $0,7 \pm 0,02$ & 1 \\
$\mathrm{Cr}$ & $0,13 \pm 0.01$ & $0,40 \pm 0,14$ & $0,60 \pm 0,10$ & $6,3 \pm 1,8$ & 0,05 \\
$\mathrm{Co}$ & $0,004 \pm 0,003$ & $0,15 \pm 0,02$ & $0,004 \pm 0,001$ & $0,084 \pm 0,024$ & 0,01 \\
$\mathrm{Mo}$ & $0,031 \pm 0,003$ & $0,13 \pm 0,002$ & $0,15 \pm 0,02$ & $0,19 \pm 0,07$ & 0,07 \\
$\mathrm{Se}$ & $0,025 \pm 0,004$ & $0,036 \pm 0,010$ & $0,026 \pm 0,006$ & $0,224 \pm 0,098$ & 0,07 \\
$\mathrm{~Pb}$ & $0,031 \pm 0,011$ & $0,162 \pm 0,026$ & $0,142 \pm 0,038$ & $0,698 \pm 0,242$ & $0,4 *$ \\
\hline
\end{tabular}

Примечания: данные представлены в виде среднего по сортам и стандартной ошибки среднего (M $\pm \mathrm{m})$. CHП - суточная норма потребления (мг) взрослого человека; *- допустимая концентрация в свежих пищевых продуктах растительного происхождения. 
Цинк, медь, кобальт и селен. Первые два элемента довольно равномерно распределены по всем тканям облепихи. При этом концентрация меди, цинка и селена в них недостаточна, чтобы отнести облепиху к реально значимым пищевым источникам этих элементов. Однако 100 г корней практически полностью обеспечивают суточную потребность человека в кобальте.

Хром. Концентрирование хрома - редкое явление в растительном мире [3]. Растения земной поверхности, как правило, накапливают хром в весьма незначительном количестве, в среднем 0,046 мг/кг сырого вещества [11]. Результаты показали, что все органы облепихи накапливают хром более интенсивно. Свежие плоды облепихи содержат 0,13 мг хрома в 1 кг, что составляет тройную суточную норму, тогда как то же количество свежих корней обеспечивает более 100 суточных норм потребления этого элемента.

Влияние почвенного загрязнения тяжелыми металлами на минеральный состав плодов облепихи (табл. 2) определялось путем сравнения их концентрации в сухом веществе из экологически чистой и придорожной зон на различном удалении растений от проезжей части [8].

Как свидетельствуют эти данные, концентрации $\mathrm{Fe}, \mathrm{Mn}, \mathrm{Cr}, \mathrm{Ni}, \mathrm{Cu}, \mathrm{Zn}$ и $\mathrm{Pb}$ в плодах из относительно чистых зон, вне зависимости от почвенно-климатических различий рассмотренных регионов, имеют весьма близкие показатели. Биологические тканевые барьеры облепихи при разных уровнях загрязнения обеспечивают в плодах относительно стабильный уровень концентрации $\mathrm{Mn}, \mathrm{Zn}$ и Со, тогда как концентрация $\mathrm{Ni}, \mathrm{Cr}$ и в особенности $\mathrm{Cu}$ и Рb существенно нарастает по мере роста загрязненности тяжелыми металлами.

По данным таблицы 3, листья облепихи накапливают существенно больше эссенциального Cr относительно других растительных видов, которые также используются в фитотерапии и для выработки БАД: жимолости синей, пятилистника кустарникового (курильского чая) и чины весенней. При этом все части растения характеризуются относительно повышенной концентрацией $\mathrm{Cr}$ (табл. 1).

Хром играет важнейшую роль в организме человека и животных, в частности, он усиливает действие инсулина в окислении глюкозы и в ряде других метаболических процессов. Питание рафинированными продуктами, избыточное количество простых углеводов в пище и все виды стресса вызывают хроническую недостаточность хрома, что способствует нарушению углеводного и жирового обмена и развитию атеросклероза [2].

Таблица 2. Концентрация и коэффициент биологического поглощения (КБП) химических элементов в сухом веществе плодов облепихи из экологически чистой зоны и в условиях техногенного загрязнения, мг/кг

\begin{tabular}{c|c|c|c|c|c|c}
\hline Элемент & Почва* & КБП,\% & Плоды & Плоды I** & Плоды II** & Плоды III** \\
\hline $\mathrm{Fe}$ & 23500 & 0,33 & 76 & 46 & 59 & 74 \\
$\mathrm{Mn}$ & 770 & 2,2 & 17 & 18 & 16 & 17 \\
$\mathrm{Cr}$ & 66 & 1,4 & 1,0 & 1,5 & 3,4 & 3,7 \\
$\mathrm{Ni}$ & 43 & 3,6 & 1,5 & 1,4 & 3,7 & 3,9 \\
$\mathrm{Cu}$ & 20 & 14 & 2,8 & 2,7 & 8,3 & 11 \\
$\mathrm{Zn}$ & 46 & 42 & 19 & 12 & 11 & 18 \\
$\mathrm{Co}$ & 9,8 & 0,3 & 0,03 & 0,3 & 0,2 & 0,3 \\
$\mathrm{~Pb}$ & 11 & 2,1 & 0,25 & 0,5 & 1,6 & 2,7 \\
\hline
\end{tabular}

Примечания. *Общая концентрация; **I,II,III - удаление от автотрассы на 10 км, 10 м и 3 м соответственно [8].

Таблица 3. Концентрация микроэлементов в листьях облепихи и других видов лекарственных растений, мг/кг сухого вещества

\begin{tabular}{c|c|c|c|c|c}
\hline Элемент & Листья облепихи & Листья жимолости [5] & Листья пятилистника [6] & Листья чины [7] & СНП \\
\hline $\mathrm{Fe}$ & $186 \pm 30$ & $59,6 \pm 6,7$ & $100 \pm 5$ & $169 \pm 8,5$ & 10 \\
$\mathrm{Mn}$ & $127 \pm 6,1$ & $86 \pm 11$ & $450 \pm 10$ & $38 \pm 1,1$ & 2 \\
$\mathrm{Zn}$ & $19 \pm 4,5$ & $19 \pm 2,6$ & $25 \pm 1$ & $20 \pm 0,8$ & 12 \\
$\mathrm{Cu}$ & $2,4 \pm 0,2$ & $3,73 \pm 0,21$ & $5,2 \pm 0,3$ & $4,1 \pm 0,3$ & 1 \\
$\mathrm{Cr}$ & $2,0 \pm 0,7$ & $0,95 \pm 0,66$ & $0,6 \pm 0,4$ & $0,9 \pm 0,5$ & 0,05 \\
$\mathrm{Co}$ & $0,07 \pm 0,01$ & $0,023 \pm 0,006$ & $\ldots$ & $0,04 \pm 0,01$ & 0,01 \\
$\mathrm{Mo}$ & $0,07 \pm 0,01$ & $0,56 \pm 0,47$ & $0,3 \pm 0,01$ & $0,1 \pm 0,004$ & 0,07 \\
$\mathrm{Se}$ & $0,18 \pm 0,05$ & $\ldots$ & $\ldots$ & $\ldots$ & 0,07 \\
$\mathrm{~Pb}$ & $0,81 \pm 0,13$ & $0,91 \pm 0,04$ & $4,6 \pm 0,5$ & $2,6 \pm 0,3$ & $6^{*}$ \\
\hline
\end{tabular}

Примечания: данные по облепихе представлены в виде среднего по сортам и стандартной ошибки среднего (M $\pm \mathrm{m})$; по 
остальным видам - в виде среднего по популяциям и стандартного отклонения $(\mathrm{M} \pm \mathrm{s})$; $\mathrm{CHП} \mathrm{-} \mathrm{суточная} \mathrm{норма} \mathrm{потреб-}$ ления (мг) взрослого человека; * - допустимая концентрация в сухих БАД из растительного сырья.

Экстракт из облепихи проявляет терапевтическую активность в отношении перечисленных выше нозологических состояний [12], поэтому есть основания предполагать, что это связано с повышенным содержанием биогенного хрома.

Поглощение свинца облепихой в естественных условиях не превышает показателей других растительных видов. Более того, надземные органы облепихи аккумулируют свинец существенно слабее среднемирового уровня его поглощения растениями (2,7 мг/кг сухого вещества) [11]. Концентрация свинца в плодах и листьях облепихи в экологически благополучных зонах (табл. 1-3) значительно ниже допустимого уровня [10]. Однако, учитывая пассивный способ поглощения свинца растениями [13], следует ожидать роста его концентрации по мере загрязнения почвы.

Всё это позволяет сделать заключение, что облепиха не относится к растениям-концентраторам свинца и более того, поглощает его существенно слабее других наземных растений.

\section{Выводbl}

1. Плоды, листья, кора и корни облепихи крушиновидной (Hippophae rhamnoides L. ssp. mongolica (Rousi)) поглощают из почвы повышенное количество хрома, что представляет интерес для использования их в производстве лечебно-профилактической продукции, обогащенной биогенным хромом.

2. Облепиха не является биологическим концентратором токсичного свинца.

\section{Список литературь}

1. Кошелев Ю.А., Агеева Л.Д. Облепиха. Бийск, 2004. 320 с.

2. Авцын А.П., Жаворонков А.А., Риш М.А., Строчкова Л.С. Микроэлементозы человека. М., 1991. 496 с.

3. Ловкова М.Я., Рабинович А.М., Пономарева С.М., Бузук Г.Н., Соколова С.М. Почему растения лечат. М., 1989. C. 24-26.

4. Дарьин А.В., Ракшун Я.В. Методика выполнения измерений при определении элементного состава образцов горных пород методом рентгенофлуоресцентного анализа с использованием синхротронного излучения из накопителя ВЭПП-3 // Научный вестник НГТУ. 2013. №2 (51). С. 119-129.

5. Боярских И.Г., Чанкина О.В., Худяев С.А., Сысо А.И. Исследование элементного состава системы почва растение на примере Lonicera caerulea L. // Известия РАН. Сер. Физическая. 2013. Т. 77. №2. С. 214-217.

6. Храмова Е.П., Чанкина О.В., Андышева Е.В., Ракшун Я.В., Сороколетов Д.С. Элементный состав рода Pentaphylloides fructicosa L. (Rosaceae) на Дальнем Востоке // Известия РАН. Сер. физическая. 2015. Т. 79. №1. C. 77-83.

7. Лобанова И.Е., Чанкина О.В. Элементный состав Lathyrus vernus (Fabaceae) // Растительный мир Азиатской России. 2012. №2 (10). С. 56-61.

8. Афанасьева Л.В., Кашин В.К. Аккумуляция тяжелых металлов в плодах Hippophae rhamnoides(Elaeagnaceae) в условиях придорожной зоны (Республика Бурятия) // Растительные ресурсы. 2015. Вып. 4. С. 554-561.

9. Методические рекомендации 2.3.1.2432-08. Нормы физиологических потребностей в энергии и пищевых веществах для различных групп населения Российской Федерации. М., 2008. С. 12-17.

10. СанПиН 2.3.2.1078-01. Гигиенические требования безопасности и пищевой ценности пищевых продуктов. М., 2002. C. $42-161$.

11. Ковальский В.В. Геохимическая экология. М., 1974. 299 с.

12. Dubey G.P., Agraval A., Sandhiya S., Ilango K., Singh R.G. Improvement in Insulin Sensitivity Following Treatment with Seabuckthorn (Hippophae L.) Extract // Seabuckthorn (Hippophae L.) A Multipurpose Wonder Plant. Vol. IV. New Delhi, 2014. Pp. 479-487.

13. Кабата-Пендиас А., Пендиас Х. Микроэлементы в почвах и растениях. М., 1989. 439 с.

Поступило в редакиию 14 сентября 2016 г. 
Skuridin G.M. ${ }^{1 *}$, Chankina O.V. ${ }^{2}$, Baginskaya $N . V^{3}{ }^{3}$ ESSENTIAL TRACE ELEMENTS AND LEAD ABSORBTION IN FRUITS AND OTHER SEA-BUCKTHORN ORGANS

${ }^{I}$ Central Siberian Botanical Garden SB RAS, ul. Zolotodolinskaya, 101, Novosibirsk, 630090 (Russia),

e-mail: skuridin@bionet.nsc.ru.

${ }^{2}$ Institute of Chemical Kinetics and Combustion SB RAS, ul. Institutskaya 3, Novosibirsk, 630090 (Russia)

${ }^{3}$ Institute of Cytology and Genetics of SB RAS, pr. Lavrentieva, 10, Novosibirsk, 630090 (Russia).

Fruits of sea-buckthorn (Hippophae rhamnoides L.) are widely used in Russia and abroad as raw material for the production of food, medicines and dietary supplements. More than 200 biologically active organic components have been found in sea-buckthorn, however its mineral composition is investigated insufficiently.

We studied elemental composition of fruit, leaves, bark and roots of several varieties of sea-buckthorn (Hippophae rhamnoides L. ssp. mongolica (Rousi)), as well as soil where they are grown. Concentration of vital (essential) $\mathrm{Fe}, \mathrm{Mn}, \mathrm{Zn}, \mathrm{Cu}$, $\mathrm{Cr}$, $\mathrm{Co}, \mathrm{Mo}$, Se and toxic $\mathrm{Pb}$ was quantified by means of XRF-SR (X-ray fluorescence analysis with synchrotron radiation) method. Intensity of elements absorption was determined by ratio of their biological uptake from soil.

All parts of sea-buckthorn are characterized by high absorption rate of chromium, lack of which contributes to development of atherosclerosis, metabolic syndrome and diabetes. Content of $\mathrm{Cr}$ exceeds widely known medicinal plants - blue honeysuckle (Lonicera caerulea ssp. altaica (Pall) and shrubby cinquefoil (Kuril tea, Pentaphylloides fructicosa (L.) Therefore, not only fruit but also leaves, bark and roots of sea-buckthorn can serve as a valuable raw material for production of medicinal and prophylactic products, enriched by nutrient chromium.

It is shown that absorption intensity of soil lead in sea-buckthorn plant parts does not exceed this parameter in other plants involved.

Keywords: sea-buckthorn, trace elements, synchrotron radiation

\section{References}

1. Koshelev Iu.A., Ageeva L.D. Oblepikha. [Sea buckthorn]. Biisk, 2004, 320 p. (in Russ.).

2. Avtsyn A.P., Zhavoronkov A.A., Rish M.A., Strochkova L.S. Mikroelementozy cheloveka. [Microelementoses person]. Moscow, 1991, 496 p. (in Russ.).

3. Lovkova M.Ia., Rabinovich A.M., Ponomareva S.M., Buzuk G.N., Sokolova S.M. Pochemu rasteniia lechat. [Why treat the plants]. Moscow, 1989, pp. 24-26. (in Russ.).

4. Dar'in A.V., Rakshun Ia.V. Nauchnyi vestnik NGTU, 2013, no. 2 (51), pp. 119-129. (in Russ.).

5. Boiarskikh I.G., Chankina O.V., Khudiaev S.A., Syso A.I. Izvestiia RAN. Ser. Fizicheskaia, 2013, vol. 77. no. 2, pp. 214-217. (in Russ.).

6. Khramova E.P., Chankina O.V., Andysheva E.V., Rakshun Ia.V., Sorokoletov D.S. Izvestiia RAN. Ser. Fizicheskaia, 2015, vol. 79, no. 1, pp. 77-83. (in Russ.).

7. Lobanova I.E., Chankina O.V. Rastitel'nyi mir aziatskoi Rossii, 2012, no. 2 (10), pp. 56-61. (in Russ.).

8. Afanas'eva L.V., Kashin V.K. Rastitel'nye resursy, 2015, no. 4, pp. 554-561. (in Russ.).

9. Metodicheskie rekomendatsii 2.3.1.2432-08. Normy fiziologicheskikh potrebnostei $v$ energii $i$ pishchevykh veshchestvakh dlia razlichnykh grupp naseleniia Rossiiskoi Federatsii. [Guidelines 2.3.1.2432-08. The norms of physiological requirements in energy and nutrients for different groups of the Russian population]. Moscow, 2008, pp. 12-17. (in Russ.).

10. SanPiN 2.3.2.1078-01. Gigienicheskie trebovaniia bezopasnosti i pishchevoi tsennosti pishchevykh produktov. [SanPiN 2.3.2.1078-01. Hygienic requirements for safety and nutritional value of food products]. Moscow, 2002, pp. 42-161. (in Russ.).

11. Koval'skii V.V. Geokhimicheskaia ekologiia. [Geochemical ecology]. Moscow, 1974, 299 p. (in Russ.).

12. Dubey G.P., Agraval A., Sandhiya S., Ilango K., Singh R.G. Seabuckthorn (Hippophae L.) A Multipurpose Wonder Plant, vol. IV, New Delhi, 2014, pp. 479-487.

13. Kabata-Pendias A., Pendias Kh. Mikroelementy v pochvakh i rasteniiakh. [Trace elements in soils and plants]. Moscow, 1989, 439 p. (in Russ.).

Received September 14, 2016

Revised November 1, 2016

\footnotetext{
* Corresponding author.
} 
